\title{
Child to parent education in prevention of acute respiratory infec-tions in rural school under rural health training centre
}

\author{
V. Mutalik A. ${ }^{{ }^{*}}{ }^{*}$, . Raje V. ${ }^{2}$ \\ DOI: https://doi.org/10.17511/ijphr.2017.i5.01 \\ 1* Anirudh V. Mutalik, Assistant Professor, Department of Community Medicine, KMCT Medical College, Calicut, Kerala, India. \\ 2 Vaishali V. Raje, Professor, Department of Community Medicine, Krishna Institute of Medical Sciences Deemed University, Karad, \\ Maharashtra, India.
}

Introduction: Acute Respiratory illness in developing countries is one of the major cause of mortality and morbidity among under five children with more than 7 million deaths every year worldwide. Most prevalent illnesses of childhood include acute respiratory tract infections, malnutrition and diarrhoeal diseases in the middle and low income countries. Aim: Aim of the study is to find out the change in level of knowledge, attitude and practice of parents after receiving health education from their school going children. Methods: A government aided higher secondary school from rural health training center of KIMS Karad was selected with the permission of headmaster of school for the study. From the school $9^{\text {th }}$ standard and their mothers were study populations which were selected by applying above exclusion criteria. A pre-structured and pretested questionnaire was used to get the information regarding definition, causes, signs, symptoms, treatment, prevention respiratory infections etc. Intervention is carried to with posttest of both students and mothers. Results: Poor and average KAP regarding Acute Respiratory Infections among children had significantly increased to Good after giving Health Education and demonstration to study group children compared to control group to whom these sessions were not conducted. Even KAP of mothers of children for whom sessions were conducted had increased significantly, from poor to good, in comparison with mothers of children for whom sessions were not conducted. Conclusion: A appropriate and holistic health education on the causation, symptoms, signs, its prevention can help in early identification of the ante respiratory diseases and hence health seeking behavior. Hence children especially the school going children can be used as an effective tool to transmit health education among the families and communities.

Keywords: ARI, Attitude, Knowledge, Mothers, Practice

Corresponding Author

Anirudh V. Mutalik, Assistant Professor, Department of Community Medicine, KMCT Medical College, Calicut, Kerala, India.

Email: dr.anirudh333@gmail.com
How to Cite this Article

Mutalik AV, Raje VV. Child to parent education in prevention of acute respiratory infec-tions in rural school under rural health training centre. Public Health Rev Int J Public Health Res. 2017;4(5):104111.

Available From

https://publichealth.medresearch.in/index.php/ijphr/ article/view/69

\section{To Browse}

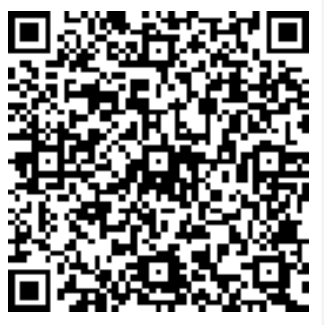

Manuscript Received 2017-10-04

Conflict of Interest No
Review Round 1 2017-10-14

Funding

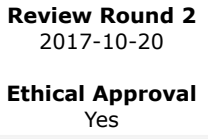

Ethical Approval Yes

Review Round 3

Plagiarism X-checker $7 \%$
Accepted 2017-10-26

Note

(c) 2017 by Anirudh V. Mutalik, Vaishali V. Raje and Published by Siddharth Health Research and Social Welfare Society. This is an Open Access article licensed under a Creative Commons Attribution 4.0 International License https://creativecommons.org/licenses/by/4.0/ unported [CC BY 4.0]. 


\section{Introduction}

Acute Respiratory illness in developing countries is one of the major cause of mortality and morbidity among under five children with more than 7 million deaths every year worldwide [1]. Most prevalent illnesses of childhood include acute respiratory tract infections, malnutrition and diarrheal diseases in the middle and low income countries [2].

Acute respiratory diseases are reported to be the 3rd leading cause of child morbidity and mortality [3]. Acute Respiratory diseases continues to affect the developing world causing in more than 3 million deaths, accounting for $15.5 \%$ of total childhood deaths i.e. under 5 years [4]. Among all developing countries India ranks 2 nd for three quarters of death due to Acute respiratory illness in under five population $[5,6]$.

One of the most important determinants of child survival is the knowledge and attitude of the Child's mother towards diseases. Mother forms the core of all families across the societies and is known to be primary caretaker of child. Hence, knowledge, attitude and health practices of mothers impacts directly on the health of the child.

Appropriate and holistic health education on the causation, symptoms, signs, its prevention can help in early identification of the ante respiratory diseases and hence health seeking behavior. This can certainly change the picture of mortality and morbidity among under five due to acute respiratory illness. Health education forms the fundamental element of primary health care.

According to the reports the incidence of acute respiratory diseases in rural India is $11.3 \%$ and in urban India is $8.5 \%$ [7]. Looking towards these figures, one can understand the prime need of improvement in health status by providing health education to the right person through the right mode.

So by educating school children we can educate their mother, father his siblings and the community. Thus school children can act as a health educator to community and be a part to prevent and control common diseases in their area. This study is an attempt to find out the effect of child to mother education particularly with regards to acute respiratory diseases in rural area.

\section{Objective}

Aim of the study was to find out the change in level of knowledge, attitude and practice of parents after receiving health education from their school going children.

To find out the existing knowledge, attitude and practice towards acute respiratory diseases among school going children and parents. To find out improvement in knowledge, attitude, practice in school children after giving health education to them. To find out the improvement in parent's knowledge, attitude and practice after providing health education to children regarding acute respiratory diseases.

\section{Material and Methods}

Type of study: Community based interventional study on school going children and their mothers.

Study area: Rural health training centre. Kasegaon under the Department of Community medicine.

Study population: Higher secondary students of Azad high school. Kasegaon

Study subjects: Students of 9th standard and their mothers.

Sample size: All the students from 9th standard were included in study after applying exclusion criteria. From both standards equal numbers of students were randomly selected to include in study \& control group. Total 148 students were found eligible and hence 74 each student was taken as study and control group for 9th standard.

\section{Exclusion criteria's:}

01 . Children of 9th standard who stays in hostel.

02. Children of 9th standard attending school from remote area of Kasegaon.

Data collection procedure: A government aided higher secondary school from rural health training centre of KIMS Karad was selected with the permission of headmaster of school for the study. From the school 9th standard and their mothers were study populations which were selected by applying above exclusion criteria.

A pre-structured and pretested questionnaire was used to get the information regarding definition, causes, signs, symptoms, treatment, prevention respiratory infections etc. 
Total 12 were questions were asked to assess KAP of which 4 for knowledge, 4 for attitude \& 4 for practice for students $\&$ in case of mothers 12 were questions were asked to assess KAP of ARI of which 4 for knowledge, 4 for attitude \& 4 for practice. Scoring system was developed to assess both pre and posttest performance of study and control group.

Correct answer was given score 1 and wrong answer and uncertain answer 0 . Grading of knowledge, attitude and practice was done as $0-1=$ Poor, $2=$ Average and 3-4 =Good. The grading for overall KAP was done as $0-3=$ Poor, 4-7=Average, 8-12= Good. This was done in consultation with statistician $\&$ with the help of reference studies number 52 .

Data related to knowledge, attitude, practice on acute respiratory infections among 9th students and mothers will be collected in predesigned and pretested questionnaire for both study and control. The mothers were interviewed personally.

Children of study group was educated regarding causes, symptoms, signs, treatment and prevention of ARI with the help of study instruments (charts, posters, demonstrations etc.). Demonstration on detection danger signals of ARTI was given in school to study subjects and assignment was given to them to perform same at home with the help of mother. The health education session was carried out 4 times in a month for 1 hour for study groups of each standard.

Different teaching techniques like experiments, drawing was used to impart health education to study group. Health education sessions were not conducted for control group. After completing health education sessions post test questionnaire was asked to be filled by children of both study and control group \&post test interview of mothers belonging to both groups were carried out.

Study instruments: Pre-structured pretested Proforma, Health education material on Acute Respiratory Infections e.g. charts, posters, lectures, power point presentations, etc

Institutional Ethical Committee clearance \& permission from school was taken before the start of study.

\section{Results}

The maximum number of children belonged to age group 15 yrs and 14 yrs.
It was observed that almost 3/4th of strength of study \& control group was due to boys. The difference between two groups was not found statistically significant. This was found to be similar with gender too. $(p>0.05)$.

According to Table I, Majority of parents had school education (Mothers 68.2\% and Father 64.2\%) whereas illiterate mothers were around one fourth $(25 \%)$. But the difference in both study and control group found statistically not significant. More than one fourth mothers of both groups were engaged in one or the other form of work. Majority of them were engaged in farm work (54.7\%) followed by labour work (23.6\%). Similarly $66.9 \%$ of fathers were engaged in farming and $23.6 \%$ in labour work.

Difference in two groups was found not significant. It was observed that nearly two third of students (72.3\%) belonged to middle class followed by lower (25.7\%) and upper class. No significant difference for Socioeconomic status observed among both study and control group. Students from both the groups were asked 12 questions to assess their knowledge, attitude and practice regarding acute respiratory disease.

Same questions were asked after imparting education and demonstration related to acute respiratory diseases. Table II showed the proportion of children given correct answers to the questions in pre test was from $0 \%$ to $68.9 \%$ in both groups. The difference was not found statistically significant $(X 2=18.74, \quad p$ value $>0.0658)$ whereas the proportions of children given correct answers was found raised in Post test among study group whereas there was almost no change or little increase in proportion of correct answers by control group $\left(X_{2}=26.612\right.$, $p$ value $\left.<0.05\right)$.

Similar to the pre test of children, pre test of mothers of both groups was carried out (Table III). In which 12 questions related to Acute respiratory infections were asked. Similar questions were asked in post test of mothers to access their Knowledge, Attitude, Practice after taking intervention. In pre test of mothers it was observed that the answers for almost all questions were proportionately same in both the groups, whereas in post test there is increase in the proportion of correct answers among mothers of study group for each question as compared to the mothers of control group.

According to table IV, percentage of parent of study and control group children given correct answers to the questions in pre test varies from $4.1 \%$ to 
Mutalik A.V. et al: Child to parent education in prevention

$52.7 \%$. The difference is not found statistically

Significant $(\mathrm{X} 2=15.562, \mathrm{p}$ value $=0.1582)$.

Table-I: Distribution according to parents Education, Occupation \& Socioeconomic Status

\begin{tabular}{|c|c|c|c|c|c|}
\hline Particulars & Study $N=74(\%)$ & Controls $\mathrm{N}=74(\%)$ & Total $N=148(\%)$ & $\mathbf{X} 2$ value & $\mathbf{p}$ value \\
\hline \multicolumn{6}{|l|}{ Mother Education } \\
\hline Illiterate & $15(20.3)$ & $22(29.7)$ & $37(25)$ & 1.972 & 0.373 \\
\hline School Education & $53(71.6)$ & $48(64.9)$ & $101(68.2)$ & & \\
\hline College Education & $6(8.1)$ & $4(5.4)$ & $10(6.8)$ & & \\
\hline \multicolumn{6}{|l|}{ Mother Occupation } \\
\hline Housewife & $10(13.5)$ & $9(14.7)$ & $19(12.8)$ & 0.885 & 0.829 \\
\hline Farmer & $39(52.7)$ & $42(41.3)$ & $81(54.7)$ & & \\
\hline Labour & $17(23)$ & $18(24.3)$ & $35(23.6)$ & & \\
\hline Professional & $8(10.8)$ & $5(6.8)$ & $13(8.8)$ & & \\
\hline \multicolumn{6}{|l|}{ Father Education } \\
\hline Illiterate & $14(18.9)$ & $14(18.9)$ & $28(18.9)$ & 2.476 & 0.290 \\
\hline School Education & $44(59.5)$ & $51(68.9)$ & $95(64.2)$ & & \\
\hline College Education & $16(21.6)$ & $9(12.2)$ & $25(16.9)$ & & \\
\hline \multicolumn{6}{|l|}{ Father Occupation } \\
\hline Farmer & $49(66.2)$ & $50(67.6)$ & $99(66.9)$ & 0.324 & 0.850 \\
\hline Labour & $17(23)$ & $18(24.3)$ & $35(23.6)$ & & \\
\hline Professional & $8(10.8)$ & $6(8.1)$ & $14(9.4)$ & & \\
\hline \multicolumn{6}{|c|}{ Socioeconomic Status } \\
\hline Upper Class & $3(4.1)$ & $0(0)$ & $3(2)$ & 3.115 & 0.211 \\
\hline Middle Class & $53(71.6)$ & $54(73.0)>$ & $107(72.3)$ & & \\
\hline Lower Class & $18(24.3)$ & $20(27)$ & $38(25.7)$ & & \\
\hline
\end{tabular}

Table-II: Proportion of correct answers by children of study \& control group for Pre \& Post-test:

\begin{tabular}{|l|l|l|l|l|l|l|}
\hline \multirow{2}{*}{ Questions SI. no. } & \multicolumn{3}{|c|}{ Correct Answers Pre Test } & \multicolumn{3}{c|}{ Correct Answers Post Test } \\
\cline { 2 - 8 } & Study $(n=74)(\%)$ & Control $(n=74)(\%)$ & Total $(n=148)(\%)$ & Study $(n=74)(\%)$ & Control $(n=74)(\%)$ & Total $(n=148)(\%)$ \\
\hline Q1 & $51(68.9)$ & $40(54.1)$ & $91(60.6)$ & $68(91.9)$ & $50(67.6)$ & $118(78.6)$ \\
\hline Q2 & $31(41.9)$ & $25(16.6)$ & $56(37.3)$ & $61(82.4)$ & $36(48.6)$ & $97(64.6)$ \\
\hline Q3 & $22(29.7)$ & $18(12)$ & $40(26.6)$ & $60(81.1)$ & $15(20.3)$ & $75(50)$ \\
\hline Q5 & $9(12.2)$ & $7(9.5)$ & $16(10.6)$ & $57(77)$ & $17(23)$ & $74(49.3)$ \\
\hline Q6 & $13(17.6)$ & $11(14.9)$ & $24(16)$ & $58(78.4)$ & $29(39.2)$ & $87(58)$ \\
\hline Q7 & $27(36.5)$ & $10(13.5)$ & $37(24.6)$ & $65(87.8)$ & $27(36.5)$ & $92(61.3)$ \\
\hline Q9 & $19(25.7)$ & $11(7.3)$ & $30(20)$ & $65(87.8)$ & $30(40.5)$ & $95(63.3)$ \\
\hline Q10 & $1(1.4)$ & $3(4.1)$ & $4(2.6)$ & $52(70.3)$ & $18(24.3)$ & $70(46.6)$ \\
\hline Q11 & $20(27)$ & $8(10.8)$ & $28(18.6)$ & $59(79.7)$ & $22(29.7)$ & $81(54)$ \\
\hline Q12 & $13(17.6)$ & $7(9.5)$ & $20(13.3)$ & $61(82.4)$ & $32(43.2)$ & $93(62)$ \\
\hline
\end{tabular}

Table-III: Proportion of Correct answers by the mothers of study \& control group in Pre \& Posttest.

\begin{tabular}{|l|l|l|l|l|l|l|}
\hline \multirow{2}{*}{ Questions S. No. } & \multicolumn{3}{|c|}{ Correct Answers Pre test } & \multicolumn{3}{c|}{ Correct Answers Post test } \\
\cline { 2 - 8 } & Study $(n=74)(\%)$ & Control $(n=74)(\%)$ & Total $(n=148)(\%)$ & Study $(n=74)(\%)$ & Control $(n=74)(\%)$ & Total $(n=148)(\%)$ \\
\hline Q1 & $39(52.7)$ & $32(43.2)$ & $71(47.3)$ & $65(87.8)$ & $34(45.9)$ & $99(66.8)$ \\
\hline Q2 & $23(31.1)$ & $21(28.4)$ & $44(29.3)$ & $53(71.6)$ & $23(31.1)$ & $76(51.3)$ \\
\hline Q3 & $18(24.3)$ & $10(14.9)$ & $28(18.6)$ & $55(74.3)$ & $12(16.2)$ & $67(45.2)$ \\
\hline Q4 & $9(12.2)$ & $7(9.5)$ & $16(10.6)$ & $53(71.6)$ & $10(13.5)$ & $56(37.3)$ \\
\hline Q6 & $19(25.6)$ & $18(24.3)$ & $37(24.5)$ & $63(85.1)$ & $21(28.3)$ & $84(56.7)$ \\
\hline
\end{tabular}


Mutalik A.V. et al: Child to parent education in prevention

\begin{tabular}{|l|l|l|l|l|l|l|}
\hline Q7 & $13(17.6)$ & $3(4.1)$ & $16(10.6)$ & $43(58)$ & $6(8.1)$ & $49(33.1)$ \\
\hline Q8 & $13(17.6)$ & $14(18.9)$ & $27(18.2)$ & $54(72.9)$ & $17(22.9)$ & $71(47.9)$ \\
\hline Q9 & $25(35.8)$ & $28(37.8)$ & $53(35.3)$ & $62(83.7)$ & $30(40.5)$ & $92(61)$ \\
\hline Q10 & $27(36.5)$ & $18(24.3)$ & $45(30)$ & $60(81)$ & $20(27)$ & $80(54)$ \\
\hline Q11 & $2(2.7)$ & $10(13.5)$ & $12(8)$ & $51(68.9)$ & $12(16.2)$ & $63(42.5)$ \\
\hline Q12 & $9(12.2)$ & $6(8.1)$ & $15(10)$ & $50(67.5)$ & $8(10.8)$ & $58(39.1)$ \\
\hline
\end{tabular}

Table-IV Comparison between pre test and post test of children and mothers

\begin{tabular}{|l|l|l|l|l|l|l|l|l|}
\hline \multirow{2}{*}{} & \multicolumn{3}{|c|}{ Children } & \multicolumn{3}{c|}{ Pother } \\
\cline { 2 - 10 } & Pre Test & \multicolumn{3}{|c|}{ Post Test } & Post Test \\
\cline { 2 - 10 } & X2 value & $\mathrm{p}$ value & X2 value & $\mathrm{p}$ value & X2 value & $\mathrm{p}$ value & X2 value & $\mathrm{p}$ value \\
\hline Knowledge & 3.377 & 0.184 & 54.931 & 0.000 & 4.572 & 0.102 & 20.549 & 0.000 \\
Attitude & 3.191 & 0.203 & 50.869 & 0.000 & 2.681 & 0.261 & 15.793 & 0.000 \\
Practice & 4.063 & 0.131 & 56.071 & 0.000 & 0.537 & 0.765 & 25.763 & 0.000 \\
Overall KAP & 1.344 & 0.246 & 58.979 & 0.000 & 3.412 & 0.182 & 29.636 & 0.000 \\
\hline
\end{tabular}

Table IV shows the comparison between $\mathrm{X}_{2}$ value and $p$ value of overall KAP scoring \& $K, A, P$ individual scoring in pre test and post test regarding KAP of Acute Respiratory Infections among study and control group of children. Table IV also shows the comparison between $X_{2}$ value and $p$ value of overall KAP scoring and Knowledge, attitude and practice scoring of mothers of both groups in pre-
And post-test regarding Acute Respiratory Infections.

From Table IV it was clear that both children and mothers in both groups were having poor to average KAP scoring but after intervention i.e. health education to study group showed significantly increased KAP score than control group which was not subjected to any intervention (Health education)

Table-V: Paired t-Test for Pre and Post Test of Children \& Mother in Study Group:

\begin{tabular}{|c|c|c|c|c|c|c|c|c|}
\hline \multirow[t]{2}{*}{ Among Study Group } & \multicolumn{3}{|c|}{ Pre test } & \multicolumn{3}{|c|}{ Post Test } & \multirow[t]{2}{*}{$t$ value } & \multirow[t]{2}{*}{ p value } \\
\hline & Min score & Max score & Mean $\pm S D$ & Min score & Max score & Mean \pm SD & & \\
\hline \multicolumn{9}{|l|}{ Children } \\
\hline Knowledge & 0 & 4 & $1.56 \pm 0.93$ & 1 & 4 & $3.22 \pm 1.20$ & 13.20 & 0.000 \\
\hline Attitude & 0 & 3 & $1.66 \pm 0.70$ & 1 & 4 & $3.24 \pm 1.00$ & 14.52 & 0.000 \\
\hline Practice & 0 & 3 & $1.70 \pm 0.61$ & 1 & 4 & $3.31 \pm 0.96$ & 13.59 & 0.000 \\
\hline Overall KAP & 0 & 7 & $4.90 \pm 2.00$ & 5 & 12 & $9.87 \pm 2.69$ & 16.18 & 0.000 \\
\hline \multicolumn{9}{|l|}{ Parent } \\
\hline Knowledge & 0 & 4 & $1.20 \pm 1.45$ & 1 & 4 & $2.72 \pm 1.32$ & 9.47 & 0.000 \\
\hline Attitude & 0 & 4 & $0.87 \pm 1.18$ & 1 & 4 & $2.48 \pm 1.48$ & 9.41 & 0.000 \\
\hline Practice & 0 & 3 & $0.85 \pm 1.09$ & 0 & 4 & $2.43 \pm 1.45$ & 11.54 & 0.000 \\
\hline Overall KAP & 0 & 8 & $2.93 \pm 2.99$ & 4 & 12 & $8.14 \pm 3.68$ & 13.02 & 0.000 \\
\hline \multicolumn{9}{|l|}{ Among Control Group } \\
\hline Children & 0 & 4 & $1.48 \pm 0.96$ & 0 & 4 & $1.59 \pm 1.43$ & 0.806 & 0.423 \\
\hline Knowledge & 0 & 4 & $1.31 \pm 0.75$ & 0 & 4 & $1.40 \pm 1.48$ & 0.583 & 0.562 \\
\hline Attitude & 0 & 3 & $1.36 \pm 0.69$ & 0 & 3 & $1.56 \pm 1.34$ & 1.277 & 0.205 \\
\hline Practice & 0 & 7 & $4.14 \pm 2.00$ & 0 & 8 & $4.56 \pm 3.46$ & 1.177 & 0.243 \\
\hline Overall KAP & & & & & & & & \\
\hline \multicolumn{9}{|l|}{ Parent } \\
\hline Knowledge & 0 & 4 & $1.52 \pm 1.21$ & 0 & 4 & $1.62 \pm 1.52$ & 0.662 & 0.510 \\
\hline Attitude & 0 & 3 & $1.29 \pm 1.04$ & 0 & 3 & $1.32 \pm 1.38$ & 0.189 & 0.850 \\
\hline Practice & 0 & 3 & $1.35 \pm 1.18$ & 0 & 3 & $1.52 \pm 1.42$ & 1.018 & 0.312 \\
\hline Overall KAP & 0 & 8 & $4.09 \pm 2.85$ & 0 & 9 & $4.47 \pm 3.91$ & 0.970 & 0.335 \\
\hline
\end{tabular}


According to Table $\mathrm{V}$, the mean scoring had increased significantly in both children and mothers of study group in whom intervention (Health education) was done, whereas mean scoring had
Not increased significantly among children and mothers of control group in whom intervention was not done (Health education) about Acute Respiratory Infections

Table-VI: Independent $t$ test showing comparison of Mean of Knowledge, Attitude and Practice between Study and control group in Pre test and Post test

\begin{tabular}{|c|c|c|c|c|c|c|c|c|}
\hline & \multicolumn{4}{|c|}{ Pre Test } & \multicolumn{4}{|c|}{ Post Test } \\
\hline & Study Mean \pm SD & Control Mean \pm SD & $t$ value & $\mathrm{p}$ value & Study Mean \pm SD & Control Mean $\pm S D$ & $t$ value & $p$ value \\
\hline \multicolumn{9}{|l|}{ Children } \\
\hline Knowledge & $1.56 \pm 0.93$ & $1.48 \pm 0.96$ & 0.517 & 0.606 & $3.32 \pm 1.20$ & $1.59 \pm 1.43$ & 7.945 & 0.000 \\
\hline Attitude & $1.33 \pm 0.84$ & $1.28 \pm 0.76$ & 0.406 & 0.685 & $3.24 \pm 1.00$ & $1.40 \pm 1.48$ & 8.803 & 0.000 \\
\hline Practice & $1.44 \pm 0.79$ & $1.35 \pm 0.71$ & 0.762 & 0.447 & $3.31 \pm 0.96$ & $1.56 \pm 1.34$ & 9.060 & 0.000 \\
\hline Overall KAP & $4.32 \pm 2.15$ & $4.10 \pm 2.01$ & 0.630 & 0.529 & $9.87 \pm 2.69$ & $4.56 \pm 3.46$ & 10.402 & 0.000 \\
\hline \multicolumn{9}{|l|}{ Parent } \\
\hline Knowledge & $1.62 \pm 1.27$ & $1.52 \pm 1.21$ & 0.461 & 0.646 & $2.72 \pm 1.34$ & $1.62 \pm 1.52$ & 4.687 & 0.000 \\
\hline Attitude & $1.28 \pm 1.06$ & $1.29 \pm 1.04$ & 0.078 & 0.938 & $2.48 \pm 1.48$ & $1.32 \pm 1.38$ & 4.926 & 0.000 \\
\hline Practice & $1.25 \pm 0.98$ & $1.35 \pm 1.18$ & 0.529 & 0.598 & $2.13 \pm 1.45$ & $1.52 \pm 1.42$ & 5.933 & 0.000 \\
\hline Overall KAP & $4.16 \pm 3.03$ & $4.09 \pm 2.85$ & 0.139 & 0.889 & $8.14 \pm 3.68$ & $4.47 \pm 3.91$ & 5.879 & 0.000 \\
\hline
\end{tabular}

Table VI shows difference in mean scoring of KAP \& overall KAP of children and their mothers of both groups. The mean of overall KAP and individual knowledge, attitude and practice score was not found having significant difference of both group among children and their mothers during pre test (Table IX).

After intervention mean score of overall KAP and individual knowledge, attitude and practice was increased among children of study group (intervention) and their mothers compared to nonintervention group (control) children and their mothers.

From Table $\mathrm{V}$ and VI it was clear that poor and average KAP regarding Acute Respiratory Infections among children had significantly increased (Good) after giving Health Education and demonstration to study group children compared to control group to whom these sessions were not conducted.

Even KAP of mothers of children for whom sessions were conducted had increased significantly, from poor to good, in comparison with mothers of children for whom sessions were not conducted.

\section{Discussion}

Mother forms the core of all families across the societies and is known to be primary caretaker of child. Hence, knowledge, attitude and health practices of mothers impacts directly on the health of the child.
A appropriate and holistic health education on the causation, symptoms, signs, its prevention can help in early identification of the ante respiratory diseases and hence health seeking behaviour. According to age group and gender, mean age was 15 years (range: 13-15). Majority of them were boys constituting $75.7 \%$ in study group as well as $71.6 \%$ in control group, girls constituted $24.3 \%$ in study group and $28.4 \%$ in control. There was no difference in study and control groups. Danielle Ferreira de Magalhães et al [8] study was conducted among students from the 5 th and 8 th grades.

Mean age reported was 10 years with range of 9-14 years in 5th grade and mean age of 14 years with range 13-17 years in the 8 th grade. There were $46.8 \%$ were boys and $53.2 \%$ girls. Compared to current study there was no difference in study as well as control group. The study of M R Savitha et al [9] reported illiteracy among mothers of $63.46 \%$ of study subjects and very less proportion of mothers with school and college education among study subjects. Huda M. Haroun et al [10]reported less proportion of maternal illiteracy(13.2\%) among study subjects. In current study $1 / 4$ th mothers were illiterates ie $20.3 \%$ in study \& $29.3 \%$ in control group students. This different observation may be existed due to different of study setting.

With respect to maternal occupation majority of mothers were farmers \& labourers whereas only minimum proportion were housewives \& professionals in both groups. 
The study done by Lloyd Angela [11], found that $11 \%$ of mothers doing agriculture work, $3.36 \%$ on daily based labour, $1.68 \%$ domestic work for others, $85.71 \%$ were housewife.

In socioeconomic status using modified B.G. Prasad classification, Maximum study group and control group from both standard belong to middle class followed by lower class and upper class. Ramesh Puri and Saroj Mehta [12] reported that 66.4\% belonged to lower class, $23.8 \%$ belong to middle class and $9.6 \%$ belong to Upper class. The different observation is due to different study setting.

\section{Pre and post test results Acute Respiratory Infections}

Among Children: The percentage of correct answers given by children in pre test and later in post test was significantly improved in study group than control group. Danielle Ferreira de Magalhães et al [8], C.E.O Reilly et al [13] ,Olajide Williams and James M. Noble [14], Christopher Vaughan et al [15] and P.R. Walvekar et al [16] also found similar improvement in post test among study group compared to control group.

The current study findings are almost similar to the studies of A. Tragler [17]\& I.O. Fawole et al[18] in which significant increase in Knowledge, Attitude, Practice after experiment (Health education) was observed.

Among Parents: The proportion of correct answers among mothers in pre test and later in post test showed significant increase in study group while in control group there was mild or almost no change suggesting that the children of study group have passed right message to the mothers.

Similarly, Danielle Ferreira de Magalhães et al [8] which involved family members observed that less proportion of correct answers before the intervention. However, at final follow-up they found increase in proportions of correct answers which were highly significant among intervention group as compared to non-intervention group.

Similar study done by C.E.O Reilly et al [13] showed improvement in Knowledge regarding correct water treatment after intervention, Elizabeth Blanton et al [19] reported that parental awareness of flocculent disinfection of water increased post intervention\& Christopher Vaughan et al [15] showed increase in number of correct answers between the pre test and post test among mothers.
All the studies reported above and the current study are suggestive of children are the best media to transfer information to the family members.

\section{Conclusion}

One of the most important determinant of child survival is the knowledge and attitude of the Child's mother towards diseases. Mother forms the core of all families across the societies and is known to be primary caretaker of child. Hence, knowledge, attitude and health practices of mothers impacts directly on the health of the child.

A appropriate and holistic health education on the causation, symptoms, signs, its prevention can help in early identification of the ante respiratory diseases and hence health seeking behaviour. Hence children especially the school going children can be used as an effective tool to transmit health education among the families and communities.

The current study adds that the children can effectively learn and be vehicle of change among the communities regarding health education.

\section{Reference}

01. Gupta N, Jain SK, Ratnesh, Chawla U, Hossain $\mathrm{S}$, Venkatesh S. An evaluation of diarrheal diseases and acute respiratory infections control programmes in a Delhi slum. Indian J Pediatr. 2007; 74(5)471-6.

[Crossref]

02. WHO. Serious childhood problem in countries with limited resources, Background book on Management of the child with serious infection or malnutrition. Geneva. 2004.

[Crossref]

03. Bhattacharya R, Kaur P. Epidemiological correlates of diarrhoea in a rural area of Varanasi. Indian Journal of Community Medicine. 1989;XIV,(2)79-82. [Crossref]

04. WHO (2008). Weekly epidemiological record, 15 th feb-2008; 7 .

Available at: [Article] [Crossref]

05. WHO (1999). Health situation in the South East Asia Region 1994-1997. Regional office for SEAR, New Delhi.

Available at: [Article] [Crossref] 
06. Mini Sheth and Monika Obrab. Diarrhoea prevention through food safety education. Indian Journal of Paediatrics. 2004;71(10)879882.

[Crossref]

07. Klepp KI, Halper A, Perry CL. The efficacy of peer leaders in drug abuse prevention. J Sch Health. 1986;56(9)407-11.

[Crossref]

08. Danielle Ferreira de Magalhães, José Ailton da Silva, João Paulo Amaral Haddad, Elvio Carlos Moreira, Maria Isabel Magalhães Fonseca, Marina Lúcia Lima de Ornelas, et al. Dissemination of information on visceral leishmaniasis from school children to their families- a sustainable model for controlling the disease. Cad Saúde Pública Rio de Janeiro. 2009;25(7)1642-1646.

[Crossref]

09. Savitha MR, Nandeshwara SB, Pradeep MJ, ulhaque $F$, Raju CK. Modifiable risk factors for acute lower respiratory tract infections. Indian journal of pediatrics. $2007 ; 74 ; 55-60$.

[Crossref]

10. Haroun HM, Mahfouz SM, Mukhtar ME, Salah A. Assessment of the effect of health education on mothers in Al Maki area, Gezira state, to improve homecare for children under five with diarrhea. Journal of Family Community Medicine. 2010;17(3)141-146.

[Crossref]

11. Lloyd Angela. "Maternal knowledge, attitudes and practices and health outcomes of their preschool-age children in urban and rural Karnataka, India" (2009). Graduate School Theses and Dissertations. 2066.

[Crossref]

12. Puri R, Mehta S. Impact of nutrition and health education on rural pre-school children. Indian journal of paediatrics. $1994 ; 31 ; 9-14$.

[Crossref]

13. O'Reilly CE, Freeman MC, Ravani M, Migele J, Mwaki A, Ayalo M, et al. The impact of a schoolbased safe water and hygiene programme on knowledge and practices of students and their parents- Nyanza Province, western Kenya, 2006. Epidemiol Infect. 2008;136(1)80-91.

[Crossref]
14. Williams O, James M. Noble 'Hip-Hop' Stroke- A Stroke Educational Program for Elementary School Children Living in a High-Risk Community American heart and stroke association. Stroke. 2008;39;2809-2816.

[Crossref]

15. Vaughan C, Gack J, Solorazano H, Ray R. The Effect of Environmental Edu-cation on Schoolchildren, Their Parents, and Community Members- A Study of Intergenerational and Inter-community Learning. The Journal of Environmental Education. 2010;34(3)12-21. [Crossref]

16. Walvekar PR, Naik VA, Wantamutte AS, Mallapur MD. Impact of child to child programme on knowledge, attitude, practice regarding diarrhoea, among rural school children. Indian Journal of Community Medicine. $2006 ; 31 ; 2 ; 56-$ 60.

[Crossref]

17. Tragler A. Health education in school children. Indian journal of Paediatrics. $1991 ; 2 ; 541-543$. [Crossref]

18. Fawole IW, Asuzu MC, Oduntan SO, Brieger WR. A School based AIDS education programme for secondary school students in Nigeria- a review of effectiveness. Journal of health education and research. $1999 ; 14(5) 675-83$.

[Crossref]

19. Blanton E, Ombeki S, Oluoch GO, Mwaki A, Wannemuehler K, Quick R. Evaluation of the Role of School Children in the Promotion of Point-of-Use Water Treatment and Handwashing in Schools and Households-Nyanza Province, Western Kenya, 2010. American Journal of Tropical Medicine and Hygiene. 2010;82(4)664671.

[Crossref] 